\title{
Sociocultural aspects of schistosomiasis mansoni in an endemic area in Minas Gerais, Brazil
}

\author{
Aspectos sócio-culturais da esquistossomose \\ mansoni em área endêmica de Minas Gerais, Brasil
}

Andréa Gazzinelli 1

Maria Flávia Gazzinelli 2

Matilde Miranda Cadete 1

Samuel Pena Filho 1

Il céia Ribei ro Sá 1

Helmut Kloos 3

\footnotetext{
1 Departamento de Enfermagem Materno Infantil, Escola de Enfermagem, Universidade Federal de Minas Gerais. Av. Alfredo Balena 190, Belo Horizonte, MG 30130-100, Brasil. 2 Departamento de Enfermagem Aplicada, Escola de Enfermagem, Universidade Federal de Minas Gerais. Av. Alfredo Balena 190, Belo Horizonte, MG 30130-100, Brasil. 3 Department of Epidemiology and Biostatistics, University of California Medical Center. San Francisco, California, 94143, USA.
}

\begin{abstract}
A study to determine the sociocultural factors influencing knowledge, attitudes, and practices of individuals from a small community toward Schistosoma mansoni infection was carried out in an endemic area in the State of Minas Gerais, Brazil. The study used qualitative approaches to collect data from school-aged children and teachers. Specific findings were that the individuals intervi ewed were aware of the disease, but also held inaccurate popular beli efs about transmission. Misconceptions coexisted with accurate knowledge both in children and teachers. The disease was not seen as a major health problem and did not affect thei $r$ activities since it did not cause severe symptoms in most of the individuals. Although the majority of the participants related transmission to water and lack of sanitation, they did not take any preventive measures since their subsi stence is highly dependent on irrigation, farming, fishing, and other essential work that is directly related to water activities. The authors discuss the development of a health education program based on the knowledge and perception of individuals about the disease and its determinants as being important for the context and behavioral change.

Key words Schistosoma mansoni; Sociocultural Factors; Health Education; Knowledge, Attitudes and Practice
\end{abstract}

Resumo Este estudo foi realizado em área endêmica do Estado de Minas Gerais, Brasil , com o obj etivo de determi nar os fatores sóci o-culturais que influenciam o conhecimento, as ati tudese práti cas dos indi víduos da comunidade em rel ação a esquistossomose mansoni. Os resultados mostraram que tanto crianças quanto professores conhecem a doença e possuem concepções corretas e incorretas sobre a transmissão. A doença não é vista como um problema importante de saúde pública e não afeta as atividades pel o fato de não causar sintomas graves na maior parte da população. Apesar da maioria dos entrevistados relacionar a transmissão da doença à água e falta de saneamento básico, não utiliza nenhuma medi da preventiva para evitar a infecção, tendo em vista que sua subsi stência depende em grande parte da agricultura, pesca e outras atividades rel aci onadas à água. Neste trabalho, os autores discutem o desenvol vi mento de um programa de educação em saúde baseado na percepção e conheci mento dos indivíduos sobre a doença e seus determinantes como sendo de utili dade para a modificação não só do seu comportamento mas também do contexto.

Palavras-chave Schistosoma mansoni; Fatores Sócio-culturais; Educação em Saúde; Conhecimentos, Atitudes e Prática 


\section{Introduction}

In Brazil, Schistosoma mansoni infection is spread mainly throughout the coastal area of the northeast region as well as in the northern portion of the State of Minas Gerais. This parasitic infection is a significant public health problem with approximately 10 million individuals infected or at risk of infection in Brazil. Schistosomiasis is a parasitic disease that causes gastrointestinal morbidity and, if not treated, may have more serious consequences, such as severe hepatomegaly, hepatosplenomegaly, esophageal varices, bleeding, and death.

Transmission can be controlled by different strategies, including drug treatment, snail control, safe water supply, sanitation, and health education. Although these methods have been used in different endemic areas, no single method has been completely satisfactory and some, such as snail control, have proven to be difficult to implement and ineffective in several endemic areas. Although chemotherapy can reduce morbidity caused by the infection, rapid reinfection occurs, mainly in children, requiring repeated treatment in endemic areas. Thus, medical intervention alone is insufficient to control the disease. Water supply management and sanitation can be effective strategies to reduce transmission (Lima e Costa et al., 1987), but their cost and the lack of political will and community motivation has made this approach difficult to implement not only in Brazil but in the majority of the endemic areas worldwide (Kloos, 1995). “Enabling factors" defined by Green et al. (1980) as availability of time, money, equipment, skills, and safe water supply, among others, must also be considered in schistosomiasis and other parasitic disease control programs (Rosenfield, 1990). Health education remains a high priority in the World Health Organization (WHO) control programs. One of its aims is to help people understand that their own behavior, including water use practices, indiscriminate defecation, and failure to seek or comply with medical treatment, are key factors in transmission of the disease.

Schistosomiasis prevalence is high in the State of Minas Gerais, ranging from 25\% to 95\% in different regions. Studies on the immune response of infected individuals are currently being undertaken in Boa União, a small rural village located in the northeast of the State. This village has a population of approximately 1,500 and a prevalence for $S$. mansoni infection of $52 \%$ in 1994 . In a recent clinical survey in Boa União, $73 \%$ of the population submitted to a medical evaluation and 20 individuals (1.9\%) were diagnosed as having hepatosplenomegaly, the severe form of the disease (Corrêa-Oliveira, R. personal communication).

Integrated studies towards the development of a health education program are being planned for schistosomiasis in the same village with the objective of reducing exposure risk to S. mansoni cercariae. It has become increasingly recognized that community-based health care programs must be designed, implemented, and evaluated within the cultural context of study communities. Many problems in primary health care programs are due to the lack of knowledge about local practices, lack of sensitivity to economic and cultural factors, and other elements that require in-depth knowledge of local cultural practices and ecological constraints (Ramakrishna et al., 1990). Designing health education programs requires consideration of the social, cultural, economic, and political factors that influence health behavior, thus providing health planners with the knowledge necessary to develop effective disease control programs. Understanding the needs, priorities, and perceptions of the community and assuring consistency of planning programs with the philosophy of health education is also of key importance for the development of planning programs that will not only be efficacious, but that will be accepted and successfully implemented, operated, and maintained (Hochbaum, 1980; Basch et al., 1986). In Brazil, Noronha et al. (1995) noted discrepancies between cultural values and habits and conventional control measures that impacted the effectiveness of health education programs. Rozemberg (1994) related snail control and other preventive measures in the national schistosomiasis control program to misconceptions about the cause and control of schistosomiasis. Thus, the objective of this study is to identify knowledge, attitudes, and practices (KAP) of teachers and students surrounding schistosomiasis transmission, prevention, and treatment in order to provide baseline information for household-based KAP and water contact studies as well as a subsequent community health education program. The results of the KAP studies will be reported elsewhere.

\section{Methodology}

Qualitative approaches were used to collect the data in semi-structured focus group discussions. Focus groups were used in this study to learn about children's and teachers' understanding of schistosomiasis transmission and 
infection in order to develop a health education program. Focus group discussions allow spontaneous discussion of ideas that may never be elicited solely by an interviewer's questions. This method is of particular value with groups of children. To understand behavior one needs to understand first the values and beliefs related to the people's practice and attitudes (Krueger, 1994).

A total of 7 focus group discussions were held with 56 volunteer children and adolescents ages 10 to 18 selected from different classes in the local school. Each group had approximately 8 participants. Three focus group discussions were also performed with a total of 15 local primary teachers that were in the school during the time of data collection. Two had bachelor degrees and the others had completed secondary education. The discussions revolved around knowledge of causes, prevention, modes of transmission, traditional therapy, and attitudes related to schistosomiasis. The focus group discussions were conducted concurrently with in-depth interviews with key people in the community such as healers, community leaders, and the local pharmacist. Written and verbal consent was obtained and all interviews were tape-recorded and transcribed verbatim. During focus group discussions, one team member, who acted as a moderator, asked questions and facilitated the discussion using the local vernacular language while the second recorded the participants' reactions. This dual method of recording responses increased data content validity and reliability and allowed comparison between audio recordings and handwritten notes. The value of focus group discussions in behavioral studies of schistosomiasis has been described by investigators in other endemic areas (El-Katsha \& Watts, 1994).

The data collected were coded and organized in 5 categories: knowledge about the disease, causes, symptoms, prevention, and treatment practices of the community. The codes for each of the above categories were identified independently by the researchers and later compared. Answers that were not related to the specific categories mentioned above were not included. Concepts arising from one focus group interview were explored with other groups and elaboration and clarification was sought from prior participants. Themes and categories were thereby generated and validated concurrently with data collection and analysis (Chenitz \& Swanson, 1986).

The analysis process started by coding the taped interview data. These codes were then examined, compared, conceptualized in regard to schistosomiasis epidemiology and prevention, and later categorized. The basic analytical process was accomplished by making comparisons for similarities and differences between each incident, event, and other data. Similar events and incidents were labeled and grouped into categories. During the initial phase, data were analyzed in detail, line by line, paragraph by paragraph. The codes were identified from interviews using the informants' own words and phrases called "in vivo" codes (Strauss \& Corbin, 1990), as shown in Table 1.

After the initial coding, events and incidents were then grouped as the categories previously selected according to the objective of the study, as shown in Table 2.

\section{Results}

Socioeconomic background of the community

Boa União is a rural community of about 1,500 people who depend largely on agriculture. Most people work as daily farm laborers or sharecroppers, growing coffee, beans, corn, and rice as well as raising cattle on the surrounding farms, requiring that many children work to supplement family incomes. A few individuals have salaries or private businesses, mostly as shop owners. Educational levels are correspondingly low. The village is bisected by three streams, all of which contain snails transmitting S. mansoni. Approximately $90 \%$ of the households had their own wells or piped supplies from nearby springs on their compounds in 1996/97. Despite this fact, it is common for people to use the streams for washing tools, fishing, and cutting grass and bushes for feeding animals. In addition, people usually stay long hours in the stream working on rice plantations. There were no sewage disposal facilities and the streams were used as the only disposal site by all houses that had latrines (approximately $90 \%$ ). A similar proportion of the households had latrines that were built with their own resources, with no assistance from the municipal government. Another sign of poor sanitation is the fact that livestock are kept on most house compounds. These animals wander freely in the streets, leaving their droppings everywhere and consuming garbage such as food remains which are often dumped just outside the compounds. All these factors generate an adverse sanitation situation which negatively affects community health. 
Table 1

Initial coding.

\begin{tabular}{|c|c|}
\hline Interview & Initial coding \\
\hline The "xistosa" is a white worm that gets inside of us. & - is a white worm \\
\hline We can get it when we wash clothes and utensils & - is a worm we have inside of us \\
\hline in the stream and when we get home we don't wash & - get "xistosa" when we wash clothes \\
\hline \multirow[t]{2}{*}{ ourselves. And that's when the worm gets inside of us. } & - get "xistosa" when we wash utensils \\
\hline & - get "xistosa" if we don't wash after being in the stream \\
\hline $\begin{array}{l}\text { We can get it also when we eat raw fish from a } \\
\text { contaminated stream full of worms and feces from } \\
\text { the latrines. }\end{array}$ & $\begin{array}{l}\text { - get "xistosa" when we eat raw fish from a contaminated } \\
\text { stream }\end{array}$ \\
\hline
\end{tabular}

Table 2

Categories.

\begin{tabular}{lc}
\hline Codes & Categories \\
\hline - is a white worm & Knowledge of the Disease \\
- is a worm we have inside of us & \\
- get "xistosa" when we wash clothes & \\
- get "xistosa" when we wash utensils & Causes of the Disease \\
- get "xistosa" if we don't wash after being in the stream & \\
- get "xistosa" when we eat raw fish from a contaminated stream & \\
\hline
\end{tabular}

\section{Knowledge of the disease}

Schistosomiasis is known by the people in Boa União as "xistosa" and was not perceived as a significant health problem, although almost all participants knew someone who had the disease. When asked about the main health problems in their families and community, participants usually referred to heart disease, diabetes, hypertension, and neurological problems. Participants perceived schistosomiasis as a disease caused by a "verme" (worm) but many of them did not know what it looks like. Some participants described the parasite as a small white worm, others believed it was long and red, and still others believed that it was invisible. These "worms" are usually seen in the stream water or well water.

\section{Cause of schistosomiasis}

There is clear unanimity with respect to the participants' beliefs about the cause of the disease. They associated schistosomiasis trans- mission with water contact activities such as washing clothes and utensils, bathing, playing, or swimming in a dirty and contaminated stream. Furthermore, they also had some inaccurate conceptions about it. It was said that transmission occurs when eating unwashed fruits and vegetables, eating fish from a contaminated stream, kissing or touching someone who has schistosomiasis, eating raw pork meat, or walking without shoes in dirty places. A few children thought that mosquitoes transmit the disease because they fly around garbage, dirty areas, and contaminated places. All these beliefs were related in general to impurities (lack of sanitation/cleanliness) and to the transmission of other common intestinal parasitic diseases, such as ascariasis, taeniasis, and others.

\section{Symptoms}

The participants related schistosomiasis symptoms to gastrointestinal problems such as stomach ache, diarrhea, bloody stools, and an enlarged belly. Both children and teachers also 
mentioned in addition to gastrointestinal symptoms others such as headache, dizziness, pain and edema in the legs, weakness, fever, and white spots on the body, mainly on the face. Enlargement and tenderness of the spleen was commonly mentioned as a sign of severe disease, based on the knowledge people had of hospitalized schistosomiasis patients, some of whom had died.

\section{Treatment and health-seeking behavior}

All participants knew about biomedical treatment for schistosomiasis although they complained about the side effects of the drugs, especially dizziness. This is apparently due to a combination of the presence of researchers from Instituto René Rachou-Fiocruz and the periodic chemotherapy they were giving to the population as part of their immunological research project and the advice given by health personnel to patients in Itabirinha de Mantena and in other towns with treatment facilities. Patients usually go first to the local pharmacist who prescribes the antischistosomal drugs after stool exams. They tend to use the health services only when they have serious gastrointestinal problems or bloody stools because of the difficulty of getting a medical appointment at the health clinic.

Boa União has no clinic, but residents use the health clinic and district hospital in the town of Itabirinha de Mantena, approximately $20 \mathrm{~km}$ away. People interviewed complained that neither the clinic nor the hospital have much to offer, especially medicines. Transportation is also difficult. Only one bus goes daily from Boa União to Itabirinha de Mantena and by the time patients get to the hospital, they report, all appointments have already been distributed. There is also a medical laboratory in the hospital, equipped for checking blood, urine, and stool samples. Patients who fail to see a doctor can either go to the hospital to obtain a medical appointment for a typically unaffordable "priority fee" or return home. Although the hospital in Itabirinha de Mantena is a public facility, patients have to pay if they want to have a regular doctor's appointment on an urgent basis.

Most individuals believed that the disease is curable with modern medicine and that it only reaches a life-threatening situation if patients do not treat it in time. Some of them knew people with schistosomiasis who had to undergo splenectomy, others that had serious gastrointestinal problems with bleeding, and some that had died. Even though they all knew that schistosomiasis is a disease that could be fatal if untreated, they did not assign much significance to it and did not take measures to prevent infection. Some participants said that it is not a serious disease like AIDS or cancer because it is curable with chemotherapy, indicating previous use of chemotherapy by the respondents. Traditional curative herbal teas were known by some, who said that they usually use them concurrently with biomedical treatment. Only few admitted that they go to local healers ("benzedeiras") for treatment. Interviews with healers established that they do not have any prayers or special remedies for "xistosa". They advise their patients to consume tea made of "Santa Maria" (Chenopodium ambrosoides), a plant known for its bitterness which is thought to kill intestinal worms in general. When patients have more serious problems and healers are unable to cure the disease, they refer them to the hospital.

\section{Prevention}

Several of the preventive measures described by the participants were similar to current public health recommendations for preventing schistosomiasis. These included building latrines, health education, and avoiding swimming in streams, rivers, and lakes that have worms and snails or are contaminated by effluents from latrines.

Other preventive measures mentioned that focus on avoiding contact activities or sources of infection reflect popular misconceptions about the transmission of schistosomiasis. Most of these apparently originated from biomedical health information about other intestinal parasites and diarrheal organisms. Cooking fish and pork before eating, keeping pots and pans in closed places, not throwing garbage into streams and rivers, and washing fruits and vegetables before eating were said to be good ways to prevent schistosomiasis. Preventive measures mentioned also reflected traditional beliefs such as that children who do not take any biomedical treatment for any parasitic disease up to age 7 will never get infected.

Most participants thought that the local mayor is responsible for the poor environmental conditions in the community. The view was commonly expressed that with piped water and sanitation facilities the percentage of people with schistosomiasis would decrease considerably. Developing sanitation facilities was said to be the mayor's responsibility. When questioned about their willingness to contribute in any way to building wells, the teach- 
ers emphasized that most people are poor and would be unable to contribute to any measure. However, this notion of helplessness is not born out by the existence of a considerable number of home-built latrines, showers, and wells in Boa União, even in poorer neighborhoods, and in the even poorer nearby village of Nova União. The observed discrepancy between teacher's and children's perceptions and actual practices and potential for community participation in water contact behavior will be reported separately.

\section{Discussion}

The main finding of this study was that the participants were aware of schistosomiasis disease and took several preventive measures, but that they also held inaccurate popular beliefs about its mode of infection and pathology. Misconceptions coexisted with accurate knowledge in both children and teachers with no clear differences between the two groups. Their knowledge about schistosomiasis was influenced by biomedical researchers from Fiocruz working in the area and probably also by local health professionals, although their relative impact cannot be discerned from our data. Although Fiocruz workers were not involved in formal educational programs' information about the transmission, cause and prevention strategies and treatment were frequently discussed informally with curious study members.

Moreover, schistosomiasis was not seen as a major health problem by the people of Boa União in spite of the high infection rates and presence of the severe form of the disease. Schistosomiasis allegedly does not affect people's activities significantly since it does not cause severe symptoms in most of the population. Only one case was reported of a teacher who had esophageal varices and decided to stop working in the rice fields to avoid reinfection. Although most participants attribute transmission to water contact and lack of sanitation, they do not relate "xistosa" to the presence of snails, unlike in the neighboring State of Espírito Santo, where the disease is known as "doença do caramujo" (snail disease), favoring the association with snail vectors (Rozemberg, 1994) and hampering preventive measures. A major reason for this difference between the two studies may be the need to continue agricultural work, fishing, and other essential water-related activities that are the basis of subsistence for the people of Boa União. The vast majority of the people in Boa Uniao, including most women and many children, appear to have frequent agricultural contacts with transmission sites at local streams. This finding was corroborated by our KAP surveys and by our epidemiological studies in Nova União, where agricultural contact was the main variable in the distribution of intensity of infection in children and fishing and agricultural contact in adults (Gazzinelli et al., 1997). Use of rubber boots during field work (currently practiced by very few individuals in Boa União) may reduce but not stop transmission since most people tend to wash themselves at the streams on their way home after working in the fields. Moreover, results of the KAP survey suggest that boots or the construction of latrines, showers, or wash basins as preventive measures are not affordable by many of the households, although it appears that the low priority given to schistosomiasis and widespread sharing of well water with neighbors and relatives, a coping behavior also documented in nearby Nova União (Gazzinelli et al., 1998), contributes to this situation. The fact that some members of households with safe well water in Nova União continue to wash clothes and utensils in the streams, because it provides plenty of water for these activities, eliminates the need to draw water from wells, and also provides opportunities for social interaction with other women, suggesting that a combination of physical environmental factors, convenience, and social needs can be more instrumental in determining water use patterns than safety factors (Gazzinelli et al., 1998).

Participants, mainly the teachers, blamed the mayor for the lack of piped water and sanitation facilities in Boa União. Village residents are not usually organized to fight for their rights and do not work as a group to pressure the authorities to live up to their promises to improve living conditions. Community organization is weak and the village was said to lack responsible community leaders. Discussions with participants indicated that people tended to remain skeptical until they see concrete control efforts undertaken by the mayor. Given these, the participants were confident that mobilizing the people for the betterment of their own lives would be feasible. Organizing the community, as well as maximizing the returns from schistosomiasis control programs will also require community participation due to the need for people to engage in the decision-making, implementation, and evaluation processes (Kloos, 1995).

No feelings of discrimination or isolation were expressed by participants infected with 
schistosomiasis, which is in contrast to the Philippines, where the disease is stigmatized, as reported by Herrin (1988). This may be due to the perception that schistosomiasis is a relatively unimportant disease that does not usually cause any major problems for patients or their kin.

It should be noted that although the community has health facilities in close proximity, people prefer to go to the pharmacist for treatment mainly because of poor access to the health clinic in Itabirinha de Mantena. Most participants reported that they get medication for schistosomiasis only during the biannual chemotherapy provided by the Project. The lack of medication for the population is also influenced by the politicians controlling the supply of drugs, chemotherapy, and the availability of health services.

The fact that individuals from the community do not feel responsible for some preventive actions related to schistosomiasis may be due to the fact that this kind of thinking occurs in a context of a Latin American country that has been subject for decades to an authoritarian government creating a political culture that is distant from the democratic ideas that stimulate people's participation. It is difficult to expect that individuals can act in a way that their actions will contribute to solve environmental problems (Sorrentino, 1991). They are usually not prepared or motivated to participate and act to solve their own problems, so it may be considered easier to transfer the responsibility for these actions to others. We should first deal with the feeling of disengagement, powerlessness, indifference, and apathy and then stimulate individuals to work together to create conditions for environmental and behavioral change.

Therefore, the health education program planned in this project based on an environmental approach and socioeconomic diagnosis promises to result in behavioral changes of individuals, since it promotes the interpretation of the reality of schistosomiasis transmission in the community, treatment of infected persons, and the building of value systems and behaviors that encourage respect for and improvements of the total village environment The environmental health education approach appears to be appropriate considering that health interventions based solely on recommending better access to health care by the population or counseling individuals about improvements in sanitary and water supply have little impact on behavior (Kloos, 1995). These strategies overlook the fact that individual san- itary measures cannot be adopted when the community has to live with inadequate health services (Oliveira, 1996) or when the way of life facilitates schistosomiasis transmission, as in Boa União and neighboring Nova União village (Gazzinelli et al., 1997). Furthermore, they tend to ignore that behavior usually reflects values and beliefs that cannot be changed without changing the cultural repertoire and informative potential of the community in relation to its own day-to-day living scenario (Ferrara, 1996; Valla, 1995).

On this specific point, Oliveira (1996) reports that the diagnosis of the basic services in the "favelas" of Rio de Janeiro was only made possible by obtaining information from subjects directly involved in the survey. These results indicate the importance of researchers being aware of the need to include social actors in their studies for immediate problem-solving. Similarly, Valla (1995), in a study in Leopoldina, Rio de Janeiro, found that health and environmental education programs failed to generate positive results in terms of behavioral change because they did not incorporate prevailing socially-approved and time-tested strategies and customs of the local people who depend on them for coping with day-to-day problems. However, it is important to emphasize that Valla (1995) taught the community concepts of hygiene and individual and environmental health in a scientifically correct and precise way.

Various studies emphasize that health education programs designed to help people to avoid passive and automated behavior related to health should not be confused with health instruction. The main difference between instruction and education is that instructions are inherently characterized by a strong normative and moralist content. Health education, in contrast, promotes critical thinking about reality, enabling individuals to judge and select behavior conducive to the exercise of citizenship and the development of the capacity to select alternative health-promoting behavior (Ferrara, 1996; Kloos, 1995).

\section{Conclusion}

The community diagnosis of this study reveals the existence of different forms of knowledge, attitudes, and both high-risk and preventive behavior in Boa União facilitating and preventing schistosomiasis transmission and spread, and that further information is needed on various aspects of the disease. Information on both 
community and individual specific causes of schistosomiasis infection, modes of transmission, and prevention needs to be especially promoted. The results also indicate the potential value of a health education program that considers prevailing knowledge, perceptions, and behaviors related to schistosomiasis with the objective of reducing contact with schistosome-infested water and facilitating healthseeking behavior. This community diagnosis may contribute to the design and implementation of such an educational program, since indepth knowledge of the target population is essential for planning health education programs in populations typically characterized by heterogeneous socioeconomic status, levels of awareness, available resource systems, priorities, concerns, fears, and other psychological

\section{Acknowledgments}

\begin{abstract}
We thank the teachers and students of Boa União for their cooperation, enthusiastic participation, and hospitality. This work was supported by Small Grants/TDR/UNDP/World Bank/WHO, Pró-Reitoria de Pesquisa da Universidade Federal de Minas Gerais-PRPq/UFM G, Fundação de Amparo a Pesquisa de Minas Gerais - Fapemig, Conselho Nacional de Desenvolvimento Científico e Tecnológico-CNPq, Programa de Apoio a Grupos de Excelência-Pronex/ $\mathrm{CNPq} /$ Finep, National Institutes of Health-NIH/ Grant Al 26505.
\end{abstract}

and social characteristics. This information may therefore promote health-enhancing learning and behavioral changes. To improve this program's chances of success, the community must also be aware that people need to develop stronger community organization, leadership, and participation to allow them to strive for better living conditions and health infrastructure using community participation. Stronger community organization and participation have the potential of helping to reduce risk behavior among people at risk of infection, especially during domestic and recreational activities. Agricultural water contact, however, the form of risk behavior most difficult to change by health education alone, may require further socioeconomic change in this predominantly subsistence farming society.

\section{References}

BASCH, C. E.; EVELAND, J. D. \& PORTNOY, B., 1986. Diffusion systems for education and learning about health. Family Community Health, 9:1-26.

CHENITZ, W. C. \& SWANSON, J. M., 1986. From Practice to Grounded Theory. Menlo Park: AddisonWesley.

EL-KATSHA, S. \& WATTS, S., 1994. A model for health education. World Health Forum, 15:29-33.

FERRARA, L., 1986. As cidades ilegíveis. In:. Percepção Ambiental (V. Rio \& L. Oliveira, orgs.), pp. 61-80, São Carlos: Universidade Federal de São Carlos.

GAZZINELLI, A.; SOUZA, M. C. C.; NASCIMENTO, I. \& KLOOS, H., 1997. Water contact, socioeconomic, water use and spatial factors in Schistosoma mansoni infection in a rural village in Brazil. 6th International Symposium on Schistosomiasis. Abstracts. Belo Horizonte.

GAZZINELLI, A.; SOUZA, M. C. C.; NASCIMENTO, I.; SÁ, I. R.; CADETE, M. M. M. \& KLOOS, H., 1998. Domestic water use in a rural village in Minas Gerais, Brazil, with an emphasis on spatial patterns, sharing of water and factors in water use. Cadernos de Saúde Pública, 14:265-278. 
GREEN, L. W.; KREUTER, M. W.; DEEDS, S. G. \& PARTRIDGE, K. B., 1980. Health Education PlanningA Diagnostic Approach. Palo Alto: Mayfield.

HERRIN, A. N., 1988. Perceptions of disease impacts: what can they tell us? In: Economics, Health and Tropical Diseases (A. N. Herrin \& P. L. Rosenfield, eds.), pp. 225-232, Manila: University of Philippines.

HOCHBAUM, G., 1980. Ethical dilemmas in health education. Health Education, 11:4-6.

KLOOS, H., 1995. Human behavior, health education and schistosomiasis control: a review. Social Science and Medicine, 40:1497-1511.

KRUEGER, R. A., 1994. Focus Groups: a Practical Guide for Applied Research. Thousand Oaks: Sage Publications.

LIMA E COSTA, M. F. F.; MAGALHÃES, M. H. A.; ROCHA, R. S.; ANTUNES, C. M. F. \& KATZ, N., 1987. Water contact patterns and socio economic variables in the epidemiology of schistosomiasis mansoni in an endemic area in Brazil. Bulletin of theWorld Health Organization, 65:57-66.

NORONHA, C. V.; BARRETTO, M. L.; SILVA, T. M. \& KATZ, N., 1995. Uma concepção popular sobre a esquistossomose mansônica: os modos de transmissão e prevenção na perspectiva de gênero. Cadernos de SaúdePública, 11:106-117.
OLIVEIRA, R., 1996. Construindo o conhecimento sobre saneamento básico nas favelas através das "falas" e informações da população. Caderno Cedes, 38:62-71.

RAM AKRISHNA, J.; BRIEGER, W. R. \& ADENIYI, J. D., 1990. Anthropology, health education, and the evolution of community control in primary health care. In: Anthropology and Primary Health Care(J. Coreil \&J. D. Mull, eds.), pp. 278-301, San Francisco: Westview Press.

ROZEMBERG, B., 1994. Representação social de eventos somáticos ligados à esquistossomose. Cadernos de Saúde Pública, 10:30-46.

ROSENFIELD, P. L., 1990. Social determinants of tropical disease. In: Tropical and Geographical Medicine (K.S. Warren \& A. A. Mahmoud, eds.), pp. 197-205, New York: McGraw Hill.

SORRENTINO, N., 1991. Educação ambiental, participação e organização de cidadãos. Em Aberto, 10:47-55.

STRAUSS, A. \& CORBIN, J., 1990. Basics of Qualitative Research: Grounded Theory Procedures and Techniques. Newbury: Park Sage.

VALLA, V., 1995. Movimentos sociais, educação popular e intelectuais: algumas questões metodológicas. 18o Encontro da Associação Nacional de Pesquisa e Pós-graduação em Educação. Resumos. Anped: Caxambu. 